\title{
Sanjad Sakati syndrome: a case series from Jordan
}

\author{
J. Albaramki, ${ }^{1}$ K. Akl, ${ }^{1}$ A. Al-Muhtaseb, ${ }^{1}$ M. Al-Shboul, ${ }^{2}$ T. Mahmoud, ${ }^{2}$ M. El-Khateeb ${ }^{2}$ and H. Hamamy ${ }^{3}$
}

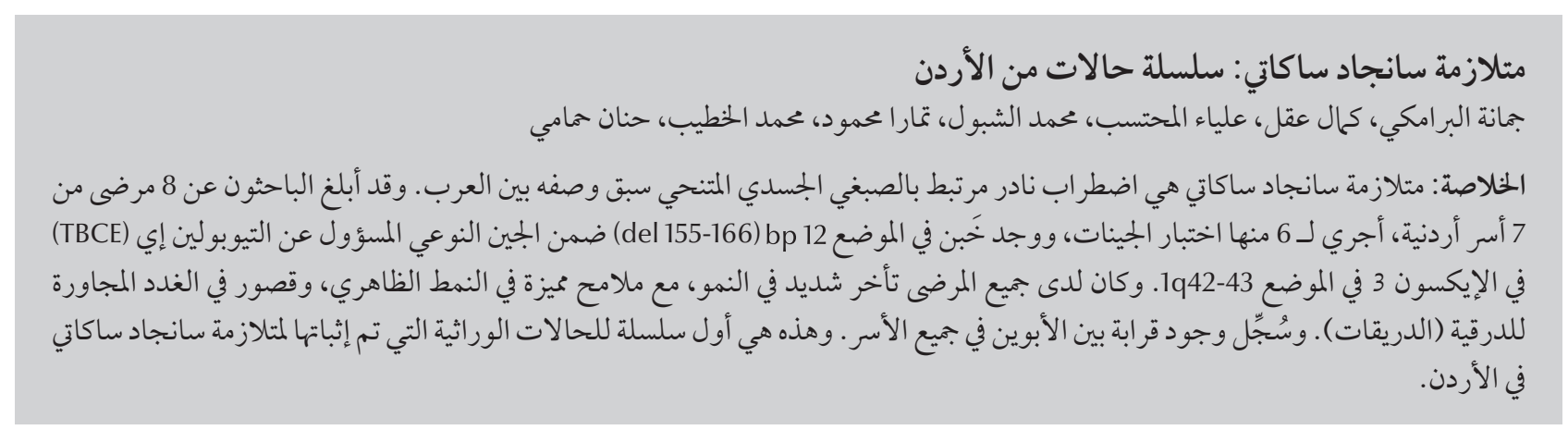

ABSTRACT Sanjad Sakati syndrome is a rare autosomal recessive disorder that has been described in Arabs. We report 8 patients from 7 Jordanian families, 6 of whom underwent genetic testing and were found to have a 12 bp (155-166 del) deletion within the tubulin-specific chaperone $\mathrm{E}$ (TBCE gene) in exon 3 at 1q42-43. All patients had severe growth retardation, distinct phenotypic features and hypoparathyroidism. Parental consanguinity was recorded in all families. This is the first genetically proven case series of Sanjad Sakati syndrome in Jordan.

\section{Le syndrome de Sanjad-Sakati : une série de cas en Jordanie}

RÉSUMÉ Le syndrome de Sanjad-Sakati est un trouble autosomique récessif rare qui a été décrit dans la population arabe. Nous avons étudié les dossiers de huit patients faisant partie de sept familles jordaniennes ; les analyses génétiques réalisées sur six d'entre eux ont révélé une délétion de 12 bp (155-166 del) dans l'exon 3 localisé en 1q42-43 dans le gène TBCE codant la protéine chaperon E spécifique de la tubuline. Tous les patients présentaient un grave retard de croissance, des caractéristiques phénotypiques singulières et une hypoparathyroïdie. Une consanguinité des parents a été observée dans toutes les familles. Il s'agit de la première série de cas du syndrome de Sanjad-Sakati confirmés génétiquement en Jordanie. 


\section{Introduction}

Sanjad Sakati syndrome or hypoparathyroidism-retardation-dysmorphism (HRD) is an autosomal recessive disorder that was first described in 1988 [1]. It is characterized by congenital hypoparathyroidism, growth and mental retardation with distinct phenotypic features. It is linked to the TBCE gene on chromosome 1q42-43 which encodes for the tubulinspecific chaperone E protein [2-4].

Sanjad Sakati syndrome has been reported in areas of the Middle East and has a high prevalence among Arabs. Since it may be confused with other syndromes that can present with hypocalcaemia and dysmorphic features, genetic testing allows Sanjad Sakati to be excluded in any child presenting with hypocalcaemia and deep-set eyes. The availability of genetic testing enables accurate diagnosis of affected children, discovery of carriers and prospective counselling as well as prenatal diagnosis of Sanjad Sakati syndrome in high-risk families.

This case series reports 8 patients with Sanjad Sakati syndrome from 7 families in Jordan, 6 of whom had genetic testing. There have been no previous reports with genetic testing from Jordan.

\section{Case series}

Hospital records were reviewed for the period 2001-2009 only these 8 cases were found. Information was extracted from the medical records and personal interview.

All the patients first presented during the neonatal period, at around 2-3 weeks of age, with hypocalcaemic seizures. Two of the patients were first seen in 2007, 2 in 2004 and 1 each in 2001, 2002, 2006, 2009. Their current mean age is 5 years (range 11 months- 10 years). There were 3 females and 5 males and 6 of them had low birth weight.

All 8 patients had measurements taken of their calcium, phosphorus and parathyroid hormone (PTH) levels; 7 had brain imaging and skeletal survey, and 3 patients had an ophthalmological assessment. All of the patients were diagnosed biochemically to have hypoparathyroidism by the low levels of PTH, hypocalcaemia and elevated phosphorus levels (Table 1). All of the patients were put on vitamin D and calcium supplements. One patient developed generalized non-uraemic calcification and another had mild bilateral medullary renal nephrocalcinosis as a complication of the treatment. One patient had refractory hyperphosphataemia.

Three patients had recurrent hospital admissions for various infections, such as pneumonia and meningitis, and 2 patients died at home in 2009 from unknown causes.

\section{Phenotypic features}

All the patients had severe failure to thrive, microcephaly, delayed motor milestones, mental retardation and learning difficulties. All of them had teeth abnormalities such as delayed teething, dental caries or abnormal teeth. They had distinct dysmorphic features including deep-set eyes, micrognathia, depressed nasal bridge, microphthalmia, prominent forehead and small hands and feet (Figure 1, Table 2).One patient had large ears and a high-arched palate.

\section{Family history}

Parental consanguinity was reported in all 7 families. The parents of 3 cases were first cousins. Three patients had a positive family history of the same condition, 2 of them were siblings. One of the patients had a sibling who had been diagnosed prenatally by genetic testing at 11 weeks of pregnancy and the mother had undergone a selective abortion of the affected fetus.

\section{Imaging results}

Seven patients underwent brain imaging: 2 cases showed bilateral symmetrical calcifications in the basal ganglia, 1 had thinning of the corpus callosum and 1 patient had craniosynostosis; the rest had normal brain imaging. Skeletal survey was normal in all patients. Bone age was assessed for 2 patients and was delayed in both.

\begin{tabular}{|c|c|c|c|c|c|c|c|c|c|}
\hline Case & Sex & $\begin{array}{l}\text { Date first } \\
\text { seen }\end{array}$ & $\begin{array}{l}\text { Calcium } \\
(\mathrm{mg} / \mathrm{dL})\end{array}$ & $\begin{array}{l}\text { Phosphorus } \\
\text { (mg/dL) }\end{array}$ & PTH & Brain CT & Consanguinity & $\begin{array}{l}\text { Genetic } \\
\text { testing }\end{array}$ & Died \\
\hline 1 & Male & Apr-2004 & 7.9 & 8.6 & Low & Not done & Second degree & Yes & - \\
\hline 2 & Male & Nov-2001 & 6.3 & 10.0 & Low & $\begin{array}{l}\text { Calcification, thin } \\
\text { corpus callosum }\end{array}$ & Second degree & No & - \\
\hline 3 & Male & Jun-2006 & 4.80 & 13.7 & Low & Normal & Second degree & No & - \\
\hline 4. & Male & Oct-2007 & 7.79 & 8.44 & Low & Normal & First degree & Yes & Yes \\
\hline 5 & Male & Aug-2007 & 8.69 & 8.58 & Low & Normal & First degree & Yes & - \\
\hline 5 & Female & Aug-2002 & 6.32 & 9.68 & Low & Normal & First degree & Yes & Yes \\
\hline 7 & Female & Aug-2009 & 4.95 & 11.95 & Low & Craniosynostosis & Second degree & Yes & - \\
\hline 8 & Female & Feb-2004 & 7.90 & 7.3 & Low & Calcification & Second degree & Yes & - \\
\hline
\end{tabular}

PTH= parathyroid hormone; $C T=$ computed tomography 


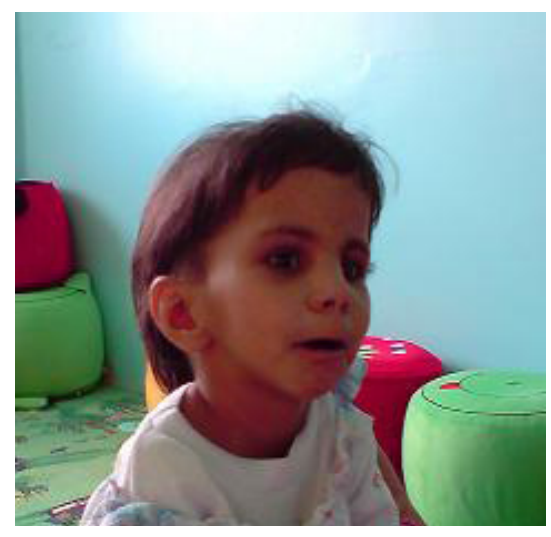

Figure 1 One of our patients with low-set ears, deep-set eyes and micrognathia: permission was granted by the family to show the photograph

\section{Ophthalmological assessment}

Ophthalmological assessment was done for 3 patients and it showed abnormal retinal vessels dilatation and tortuosity in 1, bilateral dense central corneal opacity suggestive of congenital cataract in another who needed lensectomy, and papilloedema in the third patient.

\section{Genetic testing}

EDTA-blood samples were collected from each patient at the time of presentation, and DNA was extracted using the conventional phenol-chloroform proteinase $\mathrm{K}$ method [5]. The isolated DNA was dissolved in water and diluted to a concentration of $200 \mathrm{ng} / \mu \mathrm{L}$.

Polymerase chain reaction (PCR) was performed to identify $12 \mathrm{bp}$ (155-166 del) deletion in exon 3 of the TBCE gene since this mutation has been commonly described in of Sanjad Sakati syndrome in nearby Middle Eastern countries. Samples were amplified in duplicate along with positive and negative controls. The sequence of forward and reverse PCR primer was designed by Primer 3 software. PCR reactions were carried out in $25 \mu \mathrm{L}$ reaction mixture containing $10 \mathrm{mmol} / \mathrm{L}$ Tris hydrochloride $\mathrm{pH} 8.3,50 \mathrm{mmol} / \mathrm{L}$ potassium chloride, $1.5 \mathrm{mmol} / \mathrm{L}$ magnesium chloride, $0.2 \mathrm{mmol} / \mathrm{L}$ dNTPs, $10 \mathrm{mmol} / \mathrm{L}$ primers and $1 \mathrm{U}$ of hot star Taq polymerase (Qiagen, USA). The amplification conditions used were: $95^{\circ} \mathrm{C}$ for 4 minutes, followed by $30 \mathrm{cy}$ cles at $94^{\circ} \mathrm{C}$ for 45 seconds, annealing at $62^{\circ} \mathrm{C}$ for 45 seconds and extension at $72^{\circ} \mathrm{C}$ for 1 minute. PCR products were directly run over 3\% (3:1) low electroendosmosis (LE) and low molecular

\begin{tabular}{lc}
\hline Table 2 Clinical picture of Sanjad Sakati syndrome in 8 Jordanian patients \\
\hline Feature & No. of patients \\
IUGR & 6 \\
Short stature & 8 \\
Microcephaly & 8 \\
Deep-set eyes & 8 \\
Small hands and feet & 8 \\
Hypoparathyroidism & 8 \\
Mental retardation and learning difficulties & 8 \\
Affected sibling & 3 \\
Consanguinity & 8 \\
First cousin parents & $3 / 7^{\mathrm{a}}$ \\
Second cousin parents & $4 / 7^{\mathrm{a}}$ \\
Positive genetic testing & 6 \\
Normal skeletal survey & 8 \\
Brain calcification & $2 / 7^{\mathrm{b}}$ \\
Thin corpus callosum & $1 / 7^{\mathrm{b}}$ \\
\hline
\end{tabular}

${ }^{a}$ No. offamilies assessd $=7$.

${ }^{b}$ One patient did not have brain imaging.

$I U G R=$ intrauterine growth retardation. mass polypeptide (LMP) agarose gel (Promega, USA) for 120 minutes at $80 \mathrm{~V}$ in $1 \times$ Tris boric EDTA buffer. The gel was then stained with ethidium bromide (Promega, USA), visualized by illumination with ultraviolet light, and documented by photography (Gel Doc, Bio-Rad, USA). The size of the product was about $138 \mathrm{bp}$ for the normal allele and 126 bp for the mutant allele (Figure 2).

Six patients underwent genetic testing. All of them had 12 bp (155-166 del) deletion within the TBCE gene in exon 3.

For prenatal diagnosis, around 30 mg of chorionic villi were obtained at 11 weeks of gestation using the transcervical approach. Chorionic villi were rinsed in hypotonic solution (37\% sodium chloride) and the whitish, branched tissue which represent the fetal tissue were used for DNA extraction by the phenolchloroform-proteinase K method [5].

Prenatal diagnosis was carried out for 1 case for a consanguineous couple with 2 affected children (boy and girl). The fetal sample showed homozygous deletion of the 12 bp (155-166 del) within the TBCE gene in the fetus. Both parents were heterozygous for the deletion mutation.

\section{Discussion}

This is the first genetically proven case series of Sanjad Sakati syndrome from Jordan. A recent review from Kuwait revealed a high incidence of the condition of 7-8 per 100000 live births [3].

Sanjad Sakati syndrome is a rare autosomal recessive disorder and was first described in Arabs by Sanjad et al. in Saudi Arabia in 1988 [1] and in 1991 [6], followed by reports from other countries [7-9]. In 1998, Parvari et al. used homozygosity and linkage disequilibrium to map the gene on chromosome 1q42-43 [2] and in 2002 demonstrated that mutation of the TBCE gene caused Sanjad Sakati and autosomal recessive Kenny-Caffey syndrome [3]. 


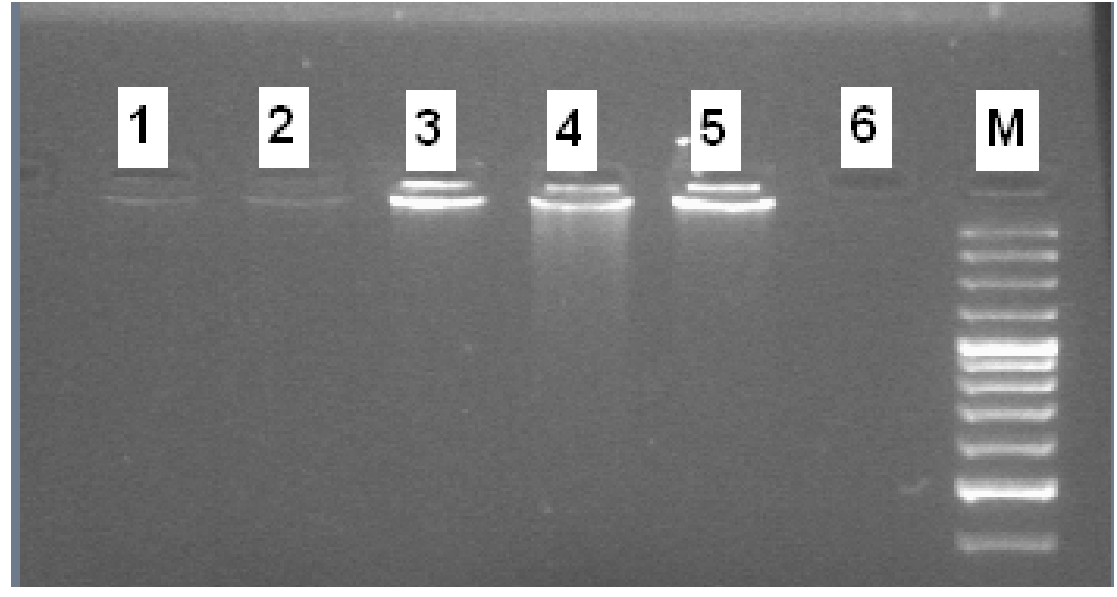

Figure 2 Lanes 1, 2, 4: homozygous for 12 bp (155-166 del) deletion; Lane 3: heterozygous for 12 bp (155-166 del) deletion; Lanes 5: negative controls; Lane 6: blank and M: 50 bp DNA ladder

The TBCE gene encodes for a protein that participates in beta tubulin folding. Homozygous deletion of $12 \mathrm{bp}$ in exon 3 of the TBCE gene was confirmed to be the cause of this syndrome (OMIM 241410) [4]. This mutation has been described in Arabs with Sanjad Sakati syndrome, but in 2006 Courten et al. described a 4.5-year-old girl with the syndrome who did not have a mutation in the TBCE gene and found another possible gene locus [10].

The syndrome can be confused with autosomal recessive Kenny-Caffey syndrome, caused by mutation in the
TBCE gene, that shares similar phenotypic features but in addition has osteosclerosis, medullary stenosis of long bones, and normal intelligence. Sanjad Sakati syndrome is characterized by congenital hypoparathyroidism, prenatal and postnatal growth retardation, developmental delay as well as mental retardation. The common dysmorphic features are microcephaly, prominent forehead, deep-set eyes, micrognathia, depressed nasal bridge, small hands and feet, dental anomalies and microphthalmia. Ophthalmic manifestations include errors of refraction, retinal vascular tortuosity, strabismus [11], and corneal opacities [12]. Thin corpus callosum has been described in patients with this syndrome [13]. Patients with Sanjad Sakati syndrome have increased susceptibility to recurrent infections but have normal immunological profile. Di George syndrome should also be considered in patients with hypoparathyroidism but these patients usually have cardiac defects and impaired immune functions and special facial features different from those found in Sanjad Sakati syndrome. Genetic testing is used to differentiate between these syndromes.

Our patients had a high rate of parental consanguinity reaching $100 \%$, much higher than the $12.5 \%$ reported in Kuwait indicating a high rate of heterozygous carriers in Kuwait [7].

The treatment of patients with Sanjad Sakati syndrome is a challenge for most physicians especially in controlling their high phosphate levels, and the adverse effects of therapy include generalized calcifications, as seen in one of our patients.

Nowadays, genetic testing for Sanjad Sakati syndrome can confirm the diagnosis and provide the option of prenatal testing in families with an affected child, or for parents with genetically proven carrier state

\section{References}

1. Sanjad S, Sakati N, Abu-Osba Y. Congenital hypoparathyroidism with dysmorphic features: a new syndrome. Pediatric Research, 1988, 23:71A

2. Parvari $\mathrm{R}$ et al. Homozygosity and linkage-disequilibrium mapping of the syndrome of congenital hypoparathyroidism, growth and mental retardation, and dysmorphism to a 1-cM interval on chromosome 1q42-43. American Journal of Human Genetics, 1998, 63:163-169.

3. Parvari $\mathrm{R}$ et al. Mutation of TBCE causes hypoparathyroidismretardation-dysmorphism and autosomal recessive KennyCaffey syndrome. Nature Genetics, 2002, 32:448-452.

4. Kelly TE et al.Confirmation of the assignment of the SanjadSakati (congenital hypoparathyroidism) syndrome (OMIM 241410) locus to chromosome lq42-43. Journal of Medical Genetics, 2000, 37 (1):63-64.

5. Sambrook J, Fritsch EF, Maniatis T. Molecular cloning: A laboratory manual, 2nd edition. Cold Spring Harbor, New York, Cold Spring Harbor Laboratory Press, 1989.
6. Sanjad SA et al. A new syndrome of congenital hypoparathyroidism, severe growth failure, and dysmorphic features. Archives of Disease in Childhood, 1991, 66(11):193-196.

7. Naguib KK et al. Sanjad-Sakati syndrome/Kenny-Caffey syndrome type 1: a study of 21 cases in Kuwait. Eastern Mediterranean Health Journal, 2009, 15(2):345-352.

8. Hershkovitz E et al.Hypoparathyroidism-retardation-Dysmorphism (HRD) syndrome-a review. Journal of Pediatric Endocrinology and Metabolism, 2004, 17 (12):1583-1590.

9. Hershkovitz E et al. The new syndrome of congenital hypoparathyroidism associated with dysmorphism, growth retardation, and developmental delay-a report of six patients. Isreal Journal of Medical Sciences, 1995, 31(5):326-327.

10. Courtens WF et al. Hypoparathyroidism-retardation-dysmorphism syndrome in a girl: A new variant not caused by a TBCE mutation--clinical report and review. American Journal of Medical Genetics, 2006, 140(6):611-617. 
11. Al Dhoyan N, Al Hemidan AI, Ozand PT. Ophthalmic manifesi tations of Sanjad-Sakati syndrome. Ophthalmic Genetics, 2006, 27(3):83-87.

12. Khan AO, Al-Assiri A, Al-Mesfer S. Ophthalmic features of hypoparathyroidism-retardation-dysmorphism. Journal of the American Association for Pediatric Ophthalmology and Strabismus, 2007,11(3): 288-290.
13. Padidela RF et al. Mutation in the TBCE gene is associated with hypoparathyroidism-retardation-dysmorphism syndrome featuring pituitary hormone deficiencies and hypoplasia of the anterior pituitary and the corpus callosum. Journal of Clinical Endocrinology and Metabolism, 2009, 94 (8):2686-2691.

\section{Community genetics services. Report of a WHO Consultation on community genetics in low-and middle- income countries. Geneva, Switzerland, 13-14 September 2010}

The above-mentioned document presents the findings and recommendations of WHO Consultation on community genetics in low- and middle-income countries. The objective of the Consultation was to develop an evidence-based report on community genetics services to provide guidance to low- and middle-income countries (LMIC) in accordance with the 2008-2013 Action Plan for the Global Strategy for the Prevention and Control of Noncommunicable Diseases. The goal of community genetics in LMIC is to prevent congenital disorders and genetic diseases at population level and, at the same time, to provide genetics services (diagnosis and counselling) in the community for individuals and families.

Congenital disorders (birth defects) constitute a major health problem worldwide especially in LMIC. Factors that may contribute to the high rates of congenital disorders in LMIC include the general low availability of public health measures directed at the care and prevention of these disorders, the high frequency of haemoglobinopathies in Africa, Middle-East and South-East Asia, the high consanguinity rates in the Eastern Mediterranean and South-East Asia regions that can increase the occurrence of recessively inherited diseases, advanced maternal age at conception in many low- and middle-income countries, which increases the predisposition to chromosomal trisomies such as Down syndrome, and large family size that may increase the number of affected children in families with autosomal recessive conditions. Prevention programmes have been successfully implemented in some LMIC, thus reducing the burden of congenital disorders or genetic diseases. Examples of countries adopting such programmes are, among others, Bahrain Cyprus and the Islamic Republic of Iran.

Further information about this and other WHO publications on genetics is available at: http:/ /www.who.int/ genomics/publications/en/index.html 